\title{
Arenimycin, an antibiotic effective against rifampin- and methicillin-resistant Staphylococcus aureus from the marine actinomycete Salinispora arenicola
}

\author{
Ratnakar N Asolkar ${ }^{1}$, Theo N Kirkland ${ }^{2}$, Paul R Jensen ${ }^{1}$ and William Fenical ${ }^{1,3}$
}

The Journal of Antibiotics (2010) 63, 37-39; doi:10.1038/ja.2009.114; published online 20 November 2009

Keywords: Salinispora arenicola; antibiotic; rifampin- and methicillin-resistant Staphylococcus aureus

\begin{abstract}
The incidence of infections by drug-resistant bacteria continues to increase and remains a serious threat to human health. In 2007, the US CDC (Centers for Disease Control and Prevention) reported that the number of serious infections caused by methicillin-resistant Staphylococcus aureus (MRSA) alone was close to 100000 a year, with almost 19000 related fatalities, a number that is larger than the US death toll attributed to HIV/AIDS (human immunodeficiency virus/acquired immunodeficiency syndrome) in the same year. ${ }^{1}$ Marine natural products offer a rich source of poorly explored bioactive molecules that are of potential value in the development of new pharmaceutical agents. ${ }^{2}$ Marine bacteria in particular have proven to be a good source of small molecules, with the vast majority of compounds being discovered from chemically prolific Gram+ bacteria belonging to the order Actinomycetales (actinomycetes). Of the marine actinomycetes from which novel natural products have been reported, the obligate marine genus Salinispora has yielded an impressive array of structurally diverse compounds including salinosporamide $A$, which is currently being used in clinical trials for the treatment of cancer. ${ }^{3}$ These compounds are produced in species-specific patterns and include potent antibiotics in the rifamycin class, which are consistently observed in extracts of Salinispora arenicola. ${ }^{4}$ In an effort to discover new antibiotics from a large collection of $S$. arenicola strains, a rifampin-resistant strain of MRSA was used to screen extracts for antibiotic activities that are derived from compounds other than rifamycins.
\end{abstract}

In total, we screened ca. 2400 crude extracts from a library that was heavily enriched with extracts collected from Salinispora species. Only six $(0.3 \%)$ of the extracts showed promising biological activity against rifampin-resistant MRSA. Among these active extracts, a liquid chromatography (LC) MS analysis of the extract of S. arenicola strain
CNR-647 showed peaks of several metabolites, some of which were identified by searching our LCMS-UV-Vis database to be known staurosporine and rifamycin analogs. However, one unknown metabolite was observed, which by its UV-Vis absorption characteristics, was observed to likely be a quinone derivative. A 51 culture broth of this organism yielded $450 \mathrm{mg}$ of crude extract, which on bioassayguided fractionation, followed by purification of the active fraction, led to the isolation of a new antibiotic, arenimycin (1, Figure 1). Arenimycin belongs to the benzo[ $\alpha]$ naphthacene quinone class of antibiotics and is most closely related to SF2446B1 (2) produced by Streptomyces sp. SF2446, which possesses a methoxyl rather than a hydroxyl substituent on the $4^{\prime}$-position of the sugar. ${ }^{5}$ This new structural derivative is the first report of this class of antibiotics from the marine actinomycete $S$. arenicola. Herein, we report the isolation, structure elucidation and potent antibiotic activity of arenimycin against a panel of drug-resistant human pathogens.

The S. arenicola strain CNR-647 was isolated from a sample of the ascidian Ecteinascidia turbinata collected from a mangrove channel at Sweetings Cay, Grand Bahama Island (tropical Atlantic Ocean) in June 2002. The animal was washed with sterile seawater, ground with an alcohol-sterilized mortar and pestle. A volume of $1 \mathrm{ml}$ of the resulting suspension was added to $4 \mathrm{ml}$ of sterile seawater, heated at $55^{\circ} \mathrm{C}$ for $6 \mathrm{~min}$, and $50 \mu \mathrm{l}$ of the resulting suspension was plated onto seawater agar containing $5 \mu \mathrm{g} \mathrm{ml}^{-1}$ rifamycin and $100 \mu \mathrm{g} \mathrm{ml}^{-1}$ cycloheximide. The strain was identified as $S$. arenicola on the basis of the $16 \mathrm{~S}$ rRNA sequence analysis (GenBank accession number FJ887039).

The CNR-647 strain was cultured in $5 \times 11$ volumes at $27^{\circ} \mathrm{C}$ for 7 days while shaking at 215 r.p.m. in the nutrient medium A1Bfe, composed of $10 \mathrm{~g}$ starch, $4 \mathrm{~g}$ yeast extract, $2 \mathrm{~g}$ peptone, $40 \mathrm{mg}$ $\mathrm{Fe}_{2}\left(\mathrm{SO}_{4}\right)_{3} 4 \mathrm{H}_{2} \mathrm{O}, 100 \mathrm{mg} \mathrm{KBr}$, per 1 liter filtered natural seawater.

${ }^{1}$ Center for Marine Biotechnology and Biomedicine, Scripps Institution of Oceanography, La Jolla, CA, USA; 2University of California, San Diego School of Medicine, and the VA San Diego Healthcare System, La Jolla, CA, USA and ${ }^{3}$ Skaggs School of Pharmacy and Pharmaceutical Sciences, University of California, San Diego, La Jolla, CA, USA Correspondence: Professor W Fenical, Center for Marine Biotechnology and Biomedicine, University of California-San Diego, 9500 Gilman Drive, La Jolla, CA 92093-0204, USA. E-mail: wfenical@ucsd.edu

Received 31 August 2009; revised 26 August 2009; accepted 28 October 2009; published online 20 November 2009 


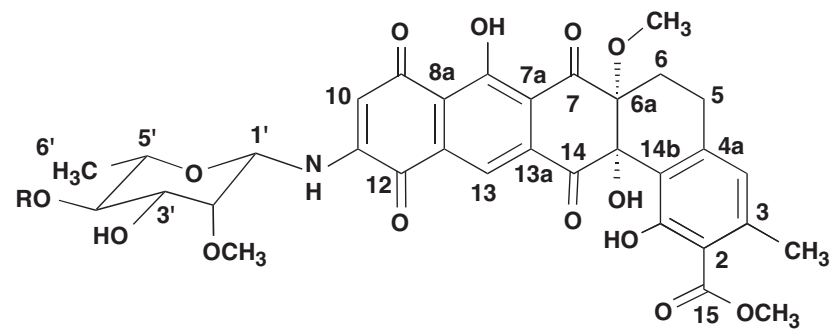

Figure 1 Structures of arenimycin $(1, \mathrm{R}=\mathrm{H})$ and $\mathrm{SF} 2446 \mathrm{~B} 1\left(2, \mathrm{R}=\mathrm{CH}_{3}\right)$.

Table 1 Physicochemical properties of 1

\begin{tabular}{ll}
\hline Appearance $^{\mathrm{a}}$ & Dark red solid, $m p=207^{\circ} \mathrm{C}$ \\
\hline HR-ESI-MS ( $\mathrm{m} / \mathrm{z})$ & {$[\mathrm{M}+\mathrm{H}]^{+}=668.2035$ for $\mathrm{C}_{33} \mathrm{H}_{33} \mathrm{O}_{14} \mathrm{~N}+\mathrm{H}$} \\
Found: ${ }^{\mathrm{b}}$ & {$[\mathrm{M}+\mathrm{Na}]^{+}=690.1753$ for $\mathrm{C}_{33} \mathrm{H}_{33} \mathrm{O}_{14} \mathrm{~N}+\mathrm{Na}$} \\
$\mathrm{UV}\left(\mathrm{CH}_{3} \mathrm{OH}\right) \lambda_{\max }$ & $216(4.23), 228(4.02), 251(3.85), 300(2.80), 415(2.18)$, \\
$(\log \varepsilon) \mathrm{nm}^{\mathrm{c}}$ & $480(2.16)$. \\
IR (thin film) $v_{\max }$ & $3450,3380,2930,1725,1675,1650,1620,1560,1509$, \\
$\mathrm{cm}^{-l_{d}}$ & $1364,1310,1260,1160,1110,950,801$.
\end{tabular}

aMelting points were determined on a Mel-Temp apparatus and are uncorrected. bHRMS were recorded on ThermoFinnigan MAT900XL (Thermo Scientific, Waltham, MA, USA) with an Agilent ESI-TOF (Agilent, Santa Clara, CA, USA) at The Scripps Research Institute, La Jolla.

cUV spectra were recorded on a Perkin-Elmer Lambda 19 UV/vis spectrophotometer (PerkinElmer, Waltham, MA, USA) with a path length of $1 \mathrm{~cm}$.

dIR spectra were acquired as a thin film ( $\mathrm{NaCl})$ on a Perkin-Elmer 1600 series FTIR spectrometer.

Amberlite XAD-7 resin $\left(20 \mathrm{gl}^{-1}\right)$ was added at the end of the fermentation period to adsorb the secreted secondary metabolites. The culture and resin were shaken at 215 r.p.m. for two additional hours. The resin and cell mass were collected by filtration through cheesecloth, and the residue was washed with DI water to remove salts. The resin, cell mass and cheesecloth were then soaked for $2 \mathrm{~h}$ in acetone. Next, the acetone extract was filtered and solvent removed under vacuum to yield $0.45 \mathrm{~g}$ of crude extract from a 51 culture.

The crude extract was fractionated by bioassay-guided methods using reversed-phase $\mathrm{C} 18$ vacuum $\mathrm{LC}\left(\mathrm{H}_{2} \mathrm{O} / \mathrm{CH}_{3} \mathrm{OH}\right.$; gradient 90:10 to $0: 100 \%)$ to yield 8 fractions. The active fraction 4 was then fractionated by preparative RP HPLC (Prep Nova-Pak HR C18, $6 \mu \mathrm{m}, 300 \times 40 \mathrm{~mm}^{2}$ ) with $\mathrm{CH}_{3} \mathrm{CN} / \mathrm{H}_{2} \mathrm{O}$ as eluent, followed by semi-preparative isocratic HPLC to yield pure arenimycin (1) as a noncrystalline red solid ( $3.5 \mathrm{mg}$, Table 1$)$.

The molecular weight of arenimycin (1) was obtained from the analysis of high-resolution electrospray ionization time-of-flight mass spectral data, which showed pseudomolecular ions at $\mathrm{m} / \mathrm{z} 668.2035$ $[\mathrm{M}+\mathrm{H}]^{+}$and $690.1753[\mathrm{M}+\mathrm{Na}]^{+}$. These data established the molecular formula of 1 as $\mathrm{C}_{33} \mathrm{H}_{33} \mathrm{O}_{14} \mathrm{~N}$, which indicated the presence of 18 double-bond equivalents. The ${ }^{13} \mathrm{C}$ NMR spectrum of 1 showed 33 signals, consistent with the molecular formula. The UV spectrum showed absorption maxima at 216, 228, 251, 300, 415 and $480 \mathrm{~nm}$ $\left(\mathrm{CH}_{3} \mathrm{OH}\right)$, which indicated the presence of a complex naphthoquinone moiety (Table 2). ${ }^{13} \mathrm{C}$ and gHSQC NMR experiments showed the presence of two methyl carbons, two methylene carbons, five methine carbons, three methoxyl carbons, two quaternary carbons, three $\mathrm{sp}^{2}$ methine carbons, eleven $\mathrm{sp}^{2}$ quaternary carbons and five carbonyl carbons. The ${ }^{1} \mathrm{H}_{-}{ }^{1} \mathrm{H}$ COSY and gHSQC NMR spectral data allowed two spin systems to be observed, an $N$-glycosyl sugar, and an ethylene unit. Detailed analysis of gHSQC, and gHMBC data from 1
Table 2 NMR spectral data for arenimycin (1) in $\mathrm{CDCl}_{3}$

\begin{tabular}{|c|c|c|c|c|c|c|}
\hline $\begin{array}{l}\text { No. } \\
\mathrm{C} / \mathrm{H}\end{array}$ & $\delta_{C}$ & & $\delta_{H}(\mathrm{~J}$ in $\mathrm{Hz})$ & $\cos Y$ & $H M B C$ & NOESY \\
\hline 1 & 160.3 & $\mathrm{C}$ & & & & \\
\hline 2 & 109.6 & C & & & & \\
\hline 3 & 142.8 & C & & & & \\
\hline 4 & 124.1 & $\mathrm{CH}$ & $6.49, \mathrm{~s}$ & $\mathrm{H}-16(w)$ & $2,5,14 b, 15,16$ & $\begin{array}{l}\mathrm{H}-5 \beta \\
\mathrm{H}-16\end{array}$ \\
\hline $4 a$ & 145.0 & $\mathrm{C}$ & & & & \\
\hline $5 \beta$ & 26.8 & $\mathrm{CH}_{2}$ & $\begin{array}{l}3.08, \text { ddd } \\
(19.2,8.6,2.0)\end{array}$ & $\mathrm{H}-6 \beta, \mathrm{H}-6 \alpha$ & $4 a, 6,6 a, 14 b$ & $\mathrm{H}-4$ \\
\hline $5 \alpha$ & & & $\begin{array}{l}3.15, \text { ddd } \\
(19.2,9.8,7.2)\end{array}$ & $\mathrm{H}-6 \beta, \mathrm{H}-6 \alpha$ & $4 a, 5,14 b$ & \\
\hline $6 \beta$ & 18.9 & $\mathrm{CH}_{2}$ & $\begin{array}{l}2.24, \mathrm{ddd} \\
(12.3,9.8,8.6)\end{array}$ & $\mathrm{H}-5 \beta, \mathrm{H}-5 \alpha$ & $5,6 a, 7$ & \\
\hline $6 \alpha$ & & & $\begin{array}{l}2.75, \text { ddd } \\
(12.3,7.2,2.0)\end{array}$ & $\mathrm{H}-5 \beta, \mathrm{H}-5 \alpha$ & $4 a, 5,6 a, 14 a$ & \\
\hline $6 a$ & 87.4 & $\mathrm{C}$ & & & & \\
\hline 7 & 190.1 & C & & & & \\
\hline $7 a$ & 124.0 & $\mathrm{C}$ & & & & \\
\hline 8 & 162.8 & C & & & & \\
\hline $8 a$ & 118.8 & C & & & & \\
\hline 9 & 189.0 & C & & & & \\
\hline 10 & 104.6 & $\mathrm{CH}$ & $5.86, \mathrm{~s}$ & & $8,8 a, 9,11,12$ & $\mathrm{H}-1^{\prime}$ \\
\hline 11 & 147.4 & $\mathrm{C}$ & & & & \\
\hline 12 & 179.1 & C & & & & \\
\hline $12 \mathrm{a}$ & 136.5 & C & & & & \\
\hline 13 & 116.2 & $\mathrm{CH}$ & $8.20, \mathrm{~s}$ & & $7 a, 8 a, 12,14$ & \\
\hline $13 a$ & 140.9 & C & & & & \\
\hline 14 & 198.1 & C & & & & \\
\hline $14 a$ & 78.0 & C & & & & \\
\hline $14 b$ & 121.2 & C & & & & \\
\hline 15 & 172.4 & C & & & & \\
\hline 16 & 23.9 & $\mathrm{CH}_{3}$ & $2.35, \mathrm{~s}$ & & $2,3,4,15$ & $\mathrm{H}-4$ \\
\hline $150 \mathrm{CH}_{3}$ & 51.9 & $\mathrm{CH}_{3}$ & $3.81, \mathrm{~s}$ & & 15 & \\
\hline $6 \mathrm{aOCH}_{3}$ & 52.2 & $\mathrm{CH}_{3}$ & $3.22, \mathrm{~s}$ & & $6 a$ & \\
\hline $1^{\prime}$ & 79.4 & $\mathrm{CH}$ & $4.69, \mathrm{~d}(9.0)$ & $\mathrm{NH}-11, \mathrm{H}-2^{\prime}$ & $2^{\prime}$ & $\begin{array}{l}\mathrm{H}-10, \mathrm{H}-2^{\prime}, \\
\mathrm{H}-5^{\prime}\end{array}$ \\
\hline $2^{\prime}$ & 80.2 & $\mathrm{CH}$ & $3.67, \mathrm{~m}$ & $\mathrm{H}-1^{\prime}, \mathrm{H}-3^{\prime}$ & $3^{\prime}, 2^{\prime}-\mathrm{OCH}_{3}$ & $\mathrm{H}-1^{\prime}, \mathrm{H}-3^{\prime}$ \\
\hline $3^{\prime}$ & 72.1 & $\mathrm{CH}$ & $3.46, \mathrm{~m}$ & $\mathrm{H}-2^{\prime}, \mathrm{H}-4^{\prime}$ & $1^{\prime}, 4^{\prime}, 5^{\prime}$ & $\mathrm{H}-2^{\prime}, \mathrm{H}-5^{\prime}$ \\
\hline $4^{\prime}$ & 75.4 & $\mathrm{CH}$ & $3.65, \mathrm{~m}$ & $\mathrm{H}-3^{\prime}, \mathrm{H}-5^{\prime}$ & $5^{\prime}$ & $H-6^{\prime}$ \\
\hline $5^{\prime}$ & 73.7 & $\mathrm{CH}$ & $\begin{array}{l}3.34, \mathrm{dq} \\
(9.2,5.9)\end{array}$ & $\mathrm{H}-4^{\prime}, \mathrm{H}-6^{\prime}$ & $3^{\prime}$ & $\mathrm{H}-1^{\prime}, \mathrm{H}-3^{\prime}$ \\
\hline $6^{\prime}$ & 18.4 & $\mathrm{CH}_{3}$ & $1.34, \mathrm{~d}(5.9)$ & $\mathrm{H}-5^{\prime}$ & $5^{\prime}, 4^{\prime}$ & $\mathrm{H}-4^{\prime}$ \\
\hline $2^{\prime} \mathrm{OCH}_{3}$ & 62.8 & $\mathrm{CH}_{3}$ & $3.75, \mathrm{~s}$ & & $2^{\prime}$ & \\
\hline $1-\mathrm{OH}$ & & & $12.0, \mathrm{~s}$ & & $1,2,3,14 b$ & \\
\hline $8-\mathrm{OH}$ & & & $14.1, \mathrm{~s}$ & & $7 a, 8,8 a$ & \\
\hline $11-\mathrm{NH}$ & & & $6.82, \mathrm{~d}(9.0)$ & $\mathrm{H}-1^{\prime}$ & $10,12,1^{\prime}$ & \\
\hline
\end{tabular}

Abbreviation: $w$, weak correlation observed.

${ }^{1} \mathrm{H},{ }^{13} \mathrm{C}$ and two-dimensional (2D) NMR spectral data were obtained on Varian Inova $500 \mathrm{MHz}$ and Varian Inova $300 \mathrm{MHz}$ NMR spectrometers (Varian, Palo Alto, CA, USA). The solvent peaks at $\delta_{\mathrm{C}} 77.0$ and $\delta_{\mathrm{H}} 7.26$ were used as chemical shift internal standards.

showed two partial structures, I and II, as shown in Figure 2. The $\mathrm{N}$ glycosyl sugar moiety of partial structure I was assigned by the analysis of combined one-dimensional (1D) and two-dimensional (2D) NMR data. The ${ }^{1} \mathrm{H}$ NMR spectrum of compound 1 showed an anomeric proton signal at $\delta 4.69\left({ }^{1} \mathrm{H}, \mathrm{d}, J=9.0 \mathrm{~Hz}\right)$ and four $-\mathrm{CH}-\mathrm{OH}$ signals between $\delta 3.67$ and $\delta 3.34$, which defined a hexopyranosyl ring. However, the carbon chemical shift for the anomeric carbon was $\delta$ 79.4 p.p.m., suggesting an $N$-substitution rather than the common $O$ substitution. On the basis of $1 \mathrm{D}$ and 2D NMR data, the sugar moiety was identified as 2'-O-methyl-rhamnopyranose. 


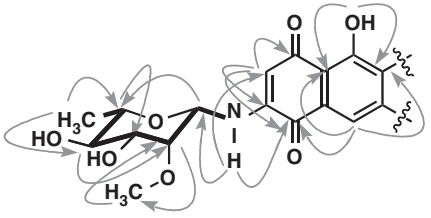

I

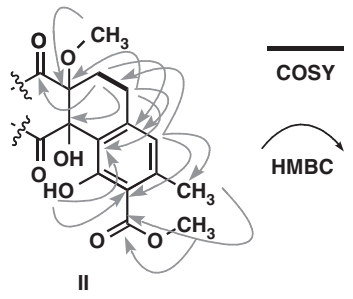

Figure 2 Key ${ }^{1} \mathrm{H}_{-}{ }^{1} \mathrm{H}$ COSY and $\mathrm{HMBC}$ correlations observed in substructures I and II for arenimycin (1).

In a similar manner, a comprehensive analysis of $2 \mathrm{D}$ NMR data (Table 2) allowed the remaining two rings of the anthraquinone substructure II to be assigned. Finally, the $\mathrm{CH}$ proton signal at $\delta$ 8.20 from substructure I, showed key HMBC correlations with the quinone carbonyl, C-14, of substructure II, and the hydroxyl at C-8 showed a weak correlation with $\mathrm{C}-7$, thus allowing these two substructures to be connected to provide structure 1 .

An AntiBase ${ }^{5}$ search with the above-mentioned carbon skeleton showed that this compound was similar to SF2446B1 (2), ${ }^{6}$ the difference between the two compounds being in the hexopyranose sugar of arenimycin (1). A literature search showed that the skeleton of quinones with this ring system are very rare in nature, only observed in collinone, ${ }^{7}$ ansacarbomitocins, ${ }^{8}$ G-2N, G-2A, ${ }^{9}$ KS-619 10 and BE-19412A. ${ }^{11}$

The overall stereostructure of $\mathbf{1}$ was assigned to be identical to that of SF2446B1. Comparison of the ${ }^{13} \mathrm{C}$ NMR data for these two metabolites showed only very minor variations in the order of $\leqslant 0.3$ p.p.m. Given the high degree of analogy, arenimycin can be assumed to have the identical stereostructure at the ring juncture as SF2446B1 (2). We attempted to record the optical rotation $\left([\alpha]_{D}\right)$ of $\mathbf{1}$, but were unable to obtain confident results because of the intense red color of this compound. The $[\alpha]_{\mathrm{D}}$ for the related compound 2 was also not reported, presumably for the same reason. The relative configuration of the anomeric carbon in the pyranohexose moiety in arenimycin (1) was assigned as $\beta$, on the basis of an observed NOE among $\mathrm{H}-1^{\prime}, \mathrm{H}-3^{\prime}$ and $\mathrm{H}-5^{\prime}$ and also from the analysis of vicinal proton coupling constants. NOE data also confirmed the relative configurations of the substituents at C-2', C- $3^{\prime}, \mathrm{C}-4^{\prime}$ and $\mathrm{C}-5^{\prime}$.

The antibiotic activities of arenimycin were evaluated using various drug-resistant Staphylococcus and Enterococcus strains, as well as the human colon adenocarcinoma cell line HCT-116. Human pathogenic bacterial strains were obtained from the Clinical Microbiology Laboratory at the San Diego VA Healthcare System. Antibacterial testing for the majority of the drug-resistant bacteria was conducted using the broth microdilution method in 96-well plates. Antibacterial activity against Mycobacterium bacille was performed using the agar dilution method with Middlebrook 7H10 agar.

In the HCT-116 adenocarcinoma cytotoxicity screen, compound 1 was a potent cell-division inhibitor showing $\mathrm{IC}_{50}=1.16 \mu \mathrm{g} \mathrm{ml}^{-1}$. Antibacterial testing with a panel of human Gram+ pathogens, such as various MRSA strains, Enterococcus feacalis and Enterococcus faecium, showed that arenimycin (1) exhibited MIC values at or $<1 \mu \mathrm{g} \mathrm{ml}^{-1}$ (Table 3). Arenimycin was not active against one vancomycin-resistant Enterococcus isolate (Table 3), but inhibited the growth of $M$. bacille Calmette Guerin at $1 \mu \mathrm{g} \mathrm{ml}^{-1}$.
Table 3 Gram-positive antimicrobial activity for arenimycin (1)

\begin{tabular}{lc}
\hline Organism (strain) & $M / C \mu g \mathrm{ml}^{-1}$ \\
\hline Rifampin and methicillin-resistant SA & 1.06 \\
MRSA (5158) & 0.53 \\
MRSA (5085) & 1.03 \\
MRSA (5167) & 0.13 \\
MRSA (5177) & 0.05 \\
MRSA (5218) & 1.00 \\
Coagulase-negative Staphylococcus (52444) & 0.05 \\
Coagulase-negative Staphylococcus (5187) & 0.05 \\
Staphylococcus saprophyticus & 0.10 \\
Enterococcus faecalis (6653-3) & 0.06 \\
Enterococcus faecium (4733) & 0.25 \\
VR E. faecium & $>8$ \\
Mycobacterium bacille (Calmette Guerin) & 1.0
\end{tabular}

Abbreviation: MRSA, methicillin-resistant Staphylococcus aureus.

In summary, we show herein that using a rifampin- and methicillinresistant $S$. aureus strain has resulted in the discovery of a new antibiotic from strains that produce significant amounts of antibiotic rifamycin derivatives. Arenimycin (1) exhibits potent antimicrobial activities against drug-resistant Staphylococci and some other Grampositive organisms and one Mycobacterium strain. The fact that arenimycin also inhibits eukaryotic cell division likely illustrates a nonselective mechanism of cytotoxic action, and may explain why this class of antibacterial agents has not been further explored.

\section{ACKNOWLEDGEMENTS}

This study is a result of financial support from the US National Institutes of Health under grant 1RO1 GM084350. We thank CA Kauffman for assistance with culturing this strain and SM Kelly for performing the cytotoxicity bioassay.

1 Taubes, G. The bacteria fight back. Science 321, 356-361 (2008).

2 Newman, D. J. \& Cragg, G. M. Natural products as sources of new drugs over the last 25 years. J. Nat. Prod. 70, 461-477 (2007)

3 Fenical, W. \& Jensen, P. R. Developing a new resource for drug discovery: marine actinomycete bacteria. Nat. Chem. Biol. 2, 666-673 (2006).

4 Jensen, P. R., Williams, P. G., Oh, D.- C., Zeigler, L. \& Fenical, W. Species-specific secondary metabolite production in marine actinomycetes of the genus Salinispora. Appl. Environ. Microbiol. 73, 1146-1152 (2007).

5 Laatsch, H. AntiBase 2005, A Data Base for Rapid Dereplication and Structure Determination of Microbial Natural Products (Wiley-VCH, Weinheim, Germany, 2005) (and annual updates); see http://wwwuser.gwdg.de/ ucoc/laatsch/AntiBase.htm.

6 Gomi, S., Sasaki, T., Itoh, J. \& Sezaki, M. SF2446, new benzo[a]naphthacene quinone antibiotics II. The structural elucidation. J. Antibiot. 41, 425-432 (1988).

7 Martin, R. et al. Collinone, a new recombinant angular polyketide antibiotic made by an engineered Streptomyces strain. J. Antibiot. 54, 239-249 (2001).

8 Snipes, C. E. et al. The ansacarbamitocins: polar ansamitocin derivatives. J. Nat. Prod. 70, 1578-1581 (2007).

9 Gerber, N. N. \& Lechevalier, M. P. Novel benzo[a]naphthacene quinone from an actinomycete, Frankia G-2 (ORS 020604). Can. J. Chem. 62, 2818-2821 (1984).

10 Yasuzawa, T., Yoshida, M., Shirahata, K. \& Sano, H. Structure of a novel Ca and calmodulin-dependent cyclic nucleotide phospodiesterase inhibitor KS-619-1. J. Antibiot. 40, 1111-1114 (1987).

11 Tsukamoto, M. et al. A new antitumor antibiotic, BE-19412A, produced by a Streptomycete. J. Antibiot. 51, 908-914 (1998). 